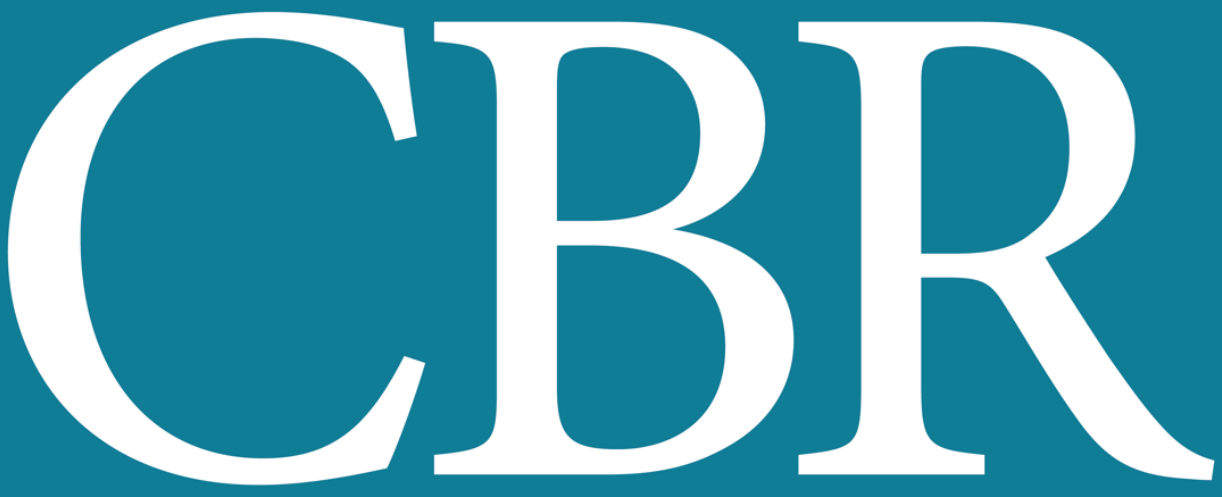

INTERNATIONAL JOURNAL OF CANCER AND BIOMEDICAL RESEARCH

https://jcbr.journals.ekb.eg

Editor-in-chief

Prof. Mohamed Labib Salem, PhD

0CT4, Ki-67 and VEGF as Prognostic Factors in Endometrial Carcinoma and Their Role in The Differentiation between Atypical Endometrial Hyperplasia and Grade 1 Endometrial Carcinoma: an Immunohistochemical study

Noha M. El -Anwar and Alaa I. Amer 


\section{Welcome letter from Editor-in-Chief}

Welcome to the Int J Cancer and Biomedical Research (IJCBR)!

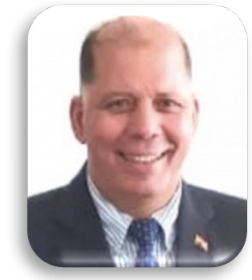

It is with great pleasure that I write this editorial to welcome you to the IJCBR. This journal provides a platform for publication of original and reviews research articles, short communications, letter to editor, thesis abstract, conference report, and case studies. These types of publication are directed at the interface of the fields of cancer and biomedical research.

The IJCBR relies on a distinguished expert of the Advisory and Editorial Board Members from the top international league covering in depth the related topics. They timely review all manuscripts and maintain highest standards of quality and scientific methodology and ethical concepts. Meanwhile, we take all possible means to keep the time of the publication process as short as possible.

I take this chance to welcome your contributions to the IJCBR and have every expectation that it will soon become one of the most respected journals in both the fields of cancer and biomedical research.

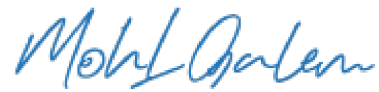

Mohamed L. Salem,

Editor in Chief 


\title{
0CT4, Ki-67 and VEGF as Prognostic Factors in Endometrial Carcinoma and Their Role in The Differentiation between Atypical Endometrial Hyperplasia and Grade 1 Endometrial Carcinoma: an Immunohistochemical study
}

\author{
Noha M. El -Anwar ${ }^{1,2}$ and Alaa I. Amer ${ }^{1}$ \\ 1 Pathology Department, Faculty of Medicine, Tanta University, Egypt \\ 2 Pathology Department, Armed Forces College of Medicine, Egypt
}

III ABSTRACT

Background: Endometrial carcinoma develops through preliminary stages of endometrial hyperplasia. A population of epithelial stem cells was identified in the human endometrium, these cells may serve as a source of putative endometrial carcinoma. The most important member of cancer stem cell markers is OCT-4. Both tumor cell proliferation (Ki-67) and angiogenesis seem to be important for the development of aggressive tumors. Aim of the Work: This study aimed to evaluate the expression of OCT4, Ki-67 and VEGF in endometrial hyperplasia and endometrial carcinoma and to differentiate between grade 1 endometrial carcinoma and atypical endometrial hyperplasia. Materials and Methods: 60 cases of endometrial hyperplasia and 60 cases of endometrial carcinoma were stained by OCT4, Ki-67and VEGF immunohistochemical markers. Results: OCT-4 expression was significantly increased with advanced tumor grade and stage $(P$ value $=0.001,0.044)$ respectively. There was also significant association between Ki-67 expression and advanced tumor grade and stage $(P$ value $=0.0016,0.049)$ respectively. VEGF expression was significantly increased with advanced tumor grade and stage ( $P$ value $=0.001)$ for both. As regards the correlation of immunohistochemical results between atypical endometrial hyperplasia versus grade 1 endometrial carcinoma cases, Ki-67 was the marker with significant relation. Conclusion: OCT-4, Ki-67 and VEGF expressions showed a positive correlation with tumor aggressive pathological parameters. The Ki-67 labelling index can be used in differentiation between endometrial hyperplasia with atypia and grade 1 endometrial carcinoma.

Keywords: Endometrial, Carcinoma, Hyperplasia, Ki-67, OCT4, VEGF

Editor-in-Chief: Prof. M.L. Salem, PhD - Article DOI: 10.21608/JCBR.2021.52448.1101

\section{ARTICLE INFO}

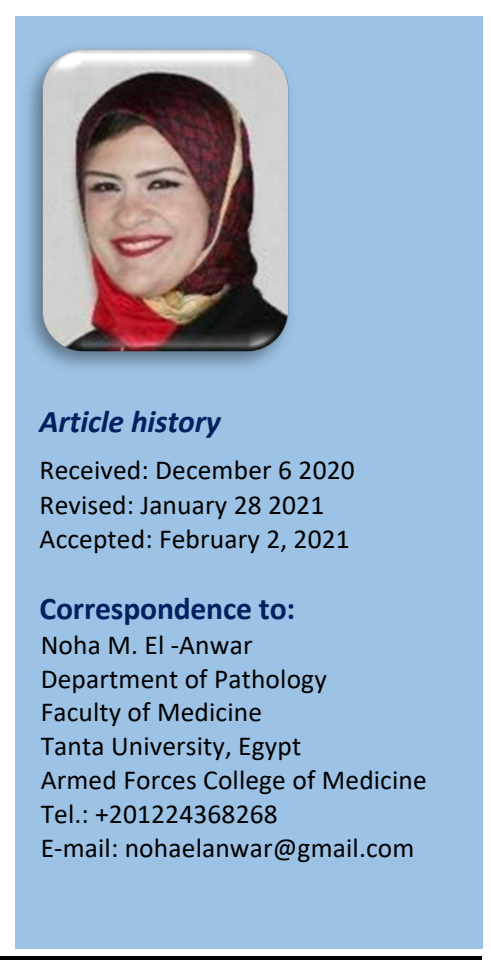

\section{INTRODUCTION}

Worldwide, endometrial carcinoma is the sixth most common malignant tumor in women. It develops through preliminary stages of endometrial hyperplasia. Accurate diagnosis and optimal treatment of endometrial hyperplastic lesions are essential to prevent endometrial carcinoma development (Malpica et al., 2019).

It may be difficult, or sometimes even impossible, in a small biopsy specimen to distinguish between atypical endometrial hyperplasia and a grade 1 endometrial carcinoma as these two lesions don't have clearly defined boundaries. In patients with a diagnosis of atypical endometrial hyperplasia on an endometrial biopsy, there is a significant risk of finding a grade 1 endometrial carcinoma in a subsequent hysterectomy specimen (Yang et al., 2020).

Several histological features help to distinguish between atypical endometrial hyperplasia and grade 1 endometrial carcinoma. The desmoplastic stromal response, back-to-back glandular architecture with complete exclusion of stroma and bridging between adjacent glands 
resulting in cribriform pattern and papillary architecture are in keeping with carcinoma. The differentiation between these two entities is important for surgical management or conservative treatment for patients wishing to preserve their childbearing potential (Murali et al.,2014).

A population of epithelial stem cells was identified recently in the human endometrium. The endometrial stem cell (ESC) associated proteins may contribute to tumorigenesis. OCT4 is transcription factors that form a core regulatory network that determines endometrial stem cell (ESC) self-renewal and differentiation. In support of this hypothesis, clinical studies have shown that elevated expression of OCT-4 is associated with different tumors e.g. retinoblastoma, prostate cancer, metastatic germ cell tumors, and ovarian cancer (Lu et al., 2020).

The Ki-67 protein is a cellular marker for proliferation. Ki-67 is an antigen present in the nuclei of cells in all phases of the cell cycle as well as in mitosis, but quiescent cells in the G0 phase do not express it. $\mathrm{Ki}-67$ is an excellent marker to determine the growth fraction of a cell population. The fraction of Ki-67 positive tumor cells (the Ki-67 labelling index) is often correlated with the clinical course of cancer. The best-studied examples in this context are carcinomas of the prostate, brain, breast and nephroblastoma (Li et al., 2013).

VEGF is important in carcinogenesis as it is responsible for the growth of the neoplasm and is also involved in the mechanism of metastasis. Angiogenesis is essential for tumor proliferation, progression and the formation of metastasis (Melincovici et al., 2018).

\section{MATERIALS AND METHODS}

This retrospective study included 60 cases of endometrial hyperplasia and 60 cases of endometrial carcinoma, total cases 120 . Formalin-fixed paraffin-embedded blocks were provided from the Pathology Department, Tanta University. Inclusion criteria included all available cases of endometrial hyperplasia and primary endometrial carcinoma. Cases without a full clinicopathological sheet or bad quality of tissue blocks were excluded. This study was performed during the period from January 2017 to June 2020. All procedures performed in the current study (specifically involving human participants) were accepted from the Local Research Ethics Committee of Faculty of Medicine, Tanta University. Detailed clinicopathologic data of these patients were obtained from their medical reports. FIGO Grading and staging of endometrial carcinoma with subtyping of cases were according to the WHO classification 2014 (Kurman et al.,2014).

\section{Immunohistochemical staining}

Formalin-fixed paraffin-embedded tissue sections $(4-\mu \mathrm{m})$ were mounted on to APES-coated glass slides (Chenglin, Shanghai, China). Slides were dewaxed in xylene twice for $10 \mathrm{~min}$ and rehydrated through graded ethanol. Antigen retrieval was performed in $0.01 \mathrm{~mol} / \mathrm{l}$ citrate buffer ( $\mathrm{pH} \mathrm{6.0)}$ by boiling for $10 \mathrm{~min}$. Endogenous peroxidase activity was suppressed with 3\% hydrogen peroxide for $10 \mathrm{~min}$. After washing with phosphate-buffered saline (PBS), the slides were blocked with 5\% BSA for 30 min at $37^{\circ} \mathrm{C}$. Sections were incubated with primary antibody to

- OCT-4 antibody was an epitope-specific purified mouse monoclonal antibody raised against the OCT-4 antigen, (CA 95677) (Cell marque, CA, USA). It was received as $7 \mathrm{~mL}$. Ready to use.

- Ki-67 (Kit no. Cat. \#RB-1510-R7 (7.0ml), labvision) (dilution 1:800)

- VEGF primary rabbit polyclonal antibody to human (Kit no. Cat. MA5-17041, Labvision), at $4^{\circ} \mathrm{C}$ overnight in a humidified chamber. After washing three times with PBS, sections were incubated for $30 \mathrm{~min}$ with the secondary antibody (peroxidase goat anti-mouse IgG; dilution, 1:300; catalog no. 32230; Zymed, San Diego, CA, USA). After washing three times in PBS, 3,3'-diaminobenzidine (as chromogen) was used. Slides were counter-stained with hematoxylin for $1 \mathrm{~min}$. Sections incubated without the primary antibody were used as negative controls.

\section{Interpretation of OCT-4 immunostaining}

OCT-4 staining was detected as brownish nuclear staining (Zhou et al., 2011) defined 
immunohistochemical scoring for OCT-4 based on the percentage of immunopositive cells into negative $(0)$, no staining in tumor cells; $(+1)$ nuclear staining in more than $10 \%$ tumor cells; and $(+2)$ nuclear staining in more than $50 \%$ tumor cells.

\section{Ki-67 labelling index}

The sections were examined at low magnifications (X40 and X100) to identify the area with the most intense staining. Only cells with a distinct nuclear Ki-67 staining were considered positive and the percentage of immunoreactive nuclei was calculated and scored as negative (no stained cells), low index ( $5 \%$ to $25 \%$ ) and high index (more than $25 \%$ ) (Masjeed et al., 2017).

\section{Interpretation of VEGF immunostaining}

VEGF was detected as cytoplasmic brownish staining. Immunostaining score was classified according to the percentage and intensity of staining into negative, weak staining in less than $10 \%$ tumor cells. Moderate staining in 11 to $50 \%$, and strong in more than $50 \%$ of tumor cells were considered as positive results, according to Guşet et al., 2010.

\section{Statistical analysis}

Statistical analysis was performed using a statistical package for the social sciences (SPSS version 23, IBM corp., Armonk, New York, USA). Categorical variables were expressed as frequencies and percentages, whereas mean \pm SD was used to express continuous variables. Chi-square $(x 2)$ Test was performed for comparing categorical variables. Fisher's exact test was applied when one of the expected frequencies was up to 5 . $P$ values of less than 0.05 were considered statistically significant and those of less than 0.001 were considered highly significant.

\section{RESULTS}

\section{Clinicopathologic Characteristics}

This study was carried on 120 specimens of endometrial lesions, which were divided into (Group I: 60 cases of endometrial hyperplasia, Group II: 60 cases with endometrial carcinoma. The mean age of endometrial hyperplasia cases was $53.88 \pm 12.36$ years (range $32-84$ ) and the mean age of endometrial carcinoma cases was
$54.77 \pm 9.81$ years (range $35-81$ ). One hundred cases complained of abnormal vaginal bleeding and discharge. Only two cases of endometrial carcinoma patients were presented with purulent vaginal discharge and a sense of pelvic pressure or discomfort. The remaining cases were found accidentally with other uterine lesions like fibroids.

\section{Histopathological and immunohistochemical}

According to WHO (2014) histopathological classification of endometrial hyperplasia cases were classified into (Kurman et al., 2014). Twenty-four cases of simple endometrial hyperplasia without atypia representing (40\%) of endometrial hyperplasia cases, 16 cases of complex endometrial hyperplasia without atypia representing $(26.7 \%)$ and 20 cases of atypical endometrial hyperplasia representing (33.3\%) of endometrial hyperplasia cases.

Endometrial carcinoma cases were classified into 38 cases of endometrioid carcinoma representing $(63.3 \%)$ of all endometrial carcinoma cases, 10 cases were clear cell endometrial carcinoma (16.7\%), 10 cases of papillary serous endometrial carcinoma (16.7\%) and 2 cases mucinous endometrial carcinoma (3.3\%).

According to the FIGO grading system (2009) of endometrial carcinoma, the included 60 cases were graded as follows: seventeen cases of well-differentiated endometrial carcinoma representing $28.3 \%$ of the total number of studied endometrial carcinoma cases, 15 cases (28.3\%) were moderately differentiated and 28 cases of poorly differentiated endometrial carcinoma representing $46.7 \%$ of the total number of the studied cases of endometrial carcinoma. Regarding myometrial invasion, 5 cases (8.3\%) were limited to the endometrium without myometrial invasion. 15 cases (25\%) invaded less than half the myometrium and 40 cases $(66.7 \%)$ invaded more than half the myometrium.

According to FIGO committee (2009) of endometrial carcinoma, the included 60 cases of endometrial carcinoma were staged as follows: Stage IA which included 20 cases (57.1\%). Stage IB included 15 cases (42.9\%.). 
Table 1.The relation between OCT-4 expression and clinicopathologic parameters of endometrial carcinoma

\begin{tabular}{|c|c|c|c|c|c|c|c|c|c|}
\hline & & & \multicolumn{5}{|c|}{ OCT -4} & \multirow{2}{*}{\multicolumn{2}{|c|}{ Chi-square }} \\
\hline & & & \multirow[b]{2}{*}{ Total $\mathbf{N}=60$} & \multirow{2}{*}{$\begin{array}{c}\text { Negative } \\
0 \\
\mathrm{~N}=8(13.3 \%)\end{array}$} & \multicolumn{3}{|c|}{ Positive N=52 (86.7\%) } & & \\
\hline & & & & & Total +ve & $\begin{array}{c}+1 \\
N=9 \\
(17.3 \%)\end{array}$ & $\begin{array}{c}+2 \\
N=43 \\
(82.7 \%)\end{array}$ & $x^{2}$ & P-value \\
\hline \multirow{8}{*}{ 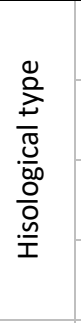 } & \multirow{2}{*}{ Endometrioid } & $\mathrm{N}$ & 38 & 8 & 30 & 8 & 22 & \multirow{8}{*}{13.572} & \multirow{8}{*}{$0.035^{*}$} \\
\hline & & $\%$ & $100.0 \%$ & $21.1 \%$ & $78.9 .0 \%$ & $26.7 \%$ & $73.3 \%$ & & \\
\hline & \multirow{2}{*}{ Mucinous } & $\mathrm{N}$ & 2 & 0 & 2 & 1 & 1 & & \\
\hline & & $\%$ & $100.0 \%$ & $0 \%$ & $100.0 \%$ & $50.0 \%$ & $50.0 \%$ & & \\
\hline & \multirow{2}{*}{ Papillary } & $\mathrm{N}$ & 10 & 0 & 10 & 0 & 10 & & \\
\hline & & $\%$ & $100.0 \%$ & $.0 \%$ & $100.0 \%$ & $.0 \%$ & $100.0 \%$ & & \\
\hline & \multirow{2}{*}{ Clear } & $\mathrm{N}$ & 10 & 0 & 10 & 0 & 10 & & \\
\hline & & $\%$ & $100.0 \%$ & $.0 \%$ & $100.0 \%$ & $.0 \%$ & $100.0 \%$ & & \\
\hline \multirow{6}{*}{$\begin{array}{l}\frac{0}{0} \\
\frac{\pi}{0}\end{array}$} & \multirow{2}{*}{1} & $\mathrm{~N}$ & 17 & 8 & 9 & 5 & 4 & \multirow{6}{*}{33.312} & \multirow{6}{*}{$0.001 *$} \\
\hline & & $\%$ & $100.0 \%$ & $47.1 \%$ & $52.9 \%$ & $55.6 \%$ & $44.4 \%$ & & \\
\hline & \multirow{2}{*}{ II } & $\mathrm{N}$ & 15 & 0 & 15 & 3 & 12 & & \\
\hline & & $\%$ & $100.0 \%$ & $.0 \%$ & $100.0 \%$ & $20.0 \%$ & $80.0 \%$ & & \\
\hline & \multirow{2}{*}{ III } & $\mathrm{N}$ & 28 & 0 & 28 & 1 & 27 & & \\
\hline & & $\%$ & $100.0 \%$ & $.0 \%$ & $100.0 \%$ & $3.6 \%$ & $96.4 \%$ & & \\
\hline \multirow{8}{*}{ 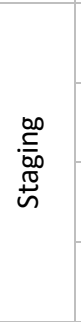 } & \multirow{2}{*}{ I } & $\mathrm{N}$ & 35 & 8 & 27 & 8 & 19 & \multirow{8}{*}{12.932} & \multirow{8}{*}{$0.044^{*}$} \\
\hline & & $\%$ & $100.0 \%$ & $22.9 \%$ & $77.1 \%$ & $29.6 \%$ & $70.4 \%$ & & \\
\hline & \multirow{2}{*}{ II } & $\mathrm{N}$ & 15 & 0 & 15 & 1 & 14 & & \\
\hline & & $\%$ & $100.0 \%$ & $.0 \%$ & $100.0 \%$ & $6.7 \%$ & $93.3 \%$ & & \\
\hline & \multirow{2}{*}{ III } & $\mathrm{N}$ & 9 & 0 & 9 & 0 & 9 & & \\
\hline & & $\%$ & $100.0 \%$ & $0 \%$ & $100.0 \%$ & $.0 \%$ & $100.0 \%$ & & \\
\hline & \multirow{2}{*}{ IV } & $\mathrm{N}$ & 1 & 0 & 1 & 0 & 1 & & \\
\hline & & $\%$ & $100.0 \%$ & $.0 \%$ & $100.0 \%$ & $.0 \%$ & $100.0 \%$ & & \\
\hline \multirow{6}{*}{ 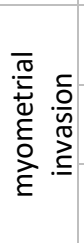 } & \multirow{2}{*}{ No } & $\mathrm{N}$ & 5 & 2 & 3 & 1 & 2 & \multirow{6}{*}{6.482} & \multirow{6}{*}{0.166} \\
\hline & & $\%$ & $100.0 \%$ & $40.0 \%$ & $60.0 \%$ & $33.3 \%$ & $66.7 \%$ & & \\
\hline & $<50$ & $\mathrm{~N}$ & 15 & 2 & 13 & 4 & 9 & & \\
\hline & $<30$ & $\%$ & $100.0 \%$ & $13.3 \%$ & $86.7 \%$ & $30.8 \%$ & $69.2 \%$ & & \\
\hline & $>50$ & $\mathrm{~N}$ & 40 & 4 & 36 & 4 & 32 & & \\
\hline & $>50$ & $\%$ & $100.0 \%$ & $10.0 \%$ & $90.0 \%$ & $11.1 \%$ & $88.9 \%$ & & \\
\hline
\end{tabular}

* Significant $(\mathrm{P}$ value $<0.05)$.

Stage II: Fifteen cases representing 25\% of endometrial carcinoma cases, included tumors invading cervical stroma, but not extending beyond the uterus. Stage III: Nine cases representing $15 \%$ of endometrial carcinoma cases. All of them were of stage IIIA, and they included tumor with invasion of serosa of the corpus. Stage IV: One case of uterine papillary serous carcinoma, representing $1.7 \%$ of endometrial carcinoma cases. It was of stage IVA, and they included tumor with invasion of bowel mucosa.

OCT4: OCT-4 expression was detected by nuclear staining in only 13 cases $(21.7 \%)$ of endometrial hyperplasia, all of them were of atypical endometrial hyperplasia and in $86.7 \%$ of endometrial carcinoma cases. The statistical analysis showed a significant direct relation between OCT-4 expression and grade of endometrial carcinoma cases, depth of myometrial invasion and stage of endometrial carcinoma cases (Figure 1 and Tables 1,4,5).

Ki-67: Low index nuclear Ki-67 expression was detected as nuclear staining in 6 cases $(10 \%)$ of endometrial hyperplasia, all of them were of atypical endometrial hyperplasia [all of these six cases were low index]. In the case of endometrial carcinoma patients, Ki-67 expression was detected in $90 \%$ of endometrial carcinoma cases. There was a statistically significant direct relation between $\mathrm{Ki}-67$ expression and histopathologic types of endometrial carcinoma cases, grading and stages were statistically significant (Figure 2 and Tables 2,4,5).

VEGF: VEGF expression was detected in $83.3 \%$ of endometrial carcinoma cases, while only 8 cases of endometrial hyperplasia cases showed 
Table 2. The relation between Ki-67 expression and clinicopathologic parameters of endometrial carcinoma.

\begin{tabular}{|c|c|c|c|c|c|c|c|c|c|}
\hline & & & \multicolumn{5}{|c|}{ Ki- 67} & \multirow{2}{*}{\multicolumn{2}{|c|}{ Chi-square }} \\
\hline & & & \multirow[b]{2}{*}{$\begin{array}{l}\text { Total } \\
\mathrm{N}=60\end{array}$} & Negative & \multicolumn{3}{|c|}{ Positive $\mathrm{N}=54(90 \%)$} & & \\
\hline & & & & $\mathrm{N}=6(10 \%)$ & Total +ve & $\begin{array}{c}\text { Low index } \\
\qquad \mathrm{N}=23 \\
(42.6 \%)\end{array}$ & $\begin{array}{l}\text { High index } \\
\qquad N=31 \\
(57.4 \%)\end{array}$ & $x^{2}$ & P-value \\
\hline \multirow{8}{*}{$\begin{array}{l}\stackrel{0}{D} \\
\frac{0}{\pi} \\
. \frac{0}{00} \\
\frac{0}{0} \\
. \frac{\mathscr{m}}{I}\end{array}$} & \multirow{2}{*}{ Endometrioid } & $\mathrm{N}$ & 38 & 6 & 32 & 22 & 10 & \multirow{8}{*}{28.781} & \multirow{8}{*}{$0.001^{*}$} \\
\hline & & $\%$ & $100.0 \%$ & $15.8 \%$ & $84.2 \%$ & $68.7 \%$ & $31.2 \%$ & & \\
\hline & \multirow{2}{*}{ Mucinous } & $\mathrm{N}$ & 2 & 0 & 2 & 1 & 1 & & \\
\hline & & $\%$ & $100.0 \%$ & $.0 \%$ & $100.0 \%$ & $50.0 \%$ & $50.0 \%$ & & \\
\hline & \multirow{2}{*}{ Papillary } & $\mathrm{N}$ & 10 & 0 & 10 & 0 & 10 & & \\
\hline & & $\%$ & $100.0 \%$ & $.0 \%$ & $100.0 \%$ & $.0 \%$ & $100.0 \%$ & & \\
\hline & \multirow{2}{*}{ Clear } & $\mathrm{N}$ & 10 & 0 & 10 & 0 & 10 & & \\
\hline & & $\%$ & $100.0 \%$ & $.0 \%$ & $100.0 \%$ & $.0 \%$ & $100.0 \%$ & & \\
\hline \multirow{6}{*}{$\begin{array}{l}\frac{0}{8} \\
\frac{\pi}{0} \\
0\end{array}$} & \multirow{2}{*}{1} & $\mathrm{~N}$ & 17 & 4 & 13 & 9 & 4 & \multirow{6}{*}{14.302} & \multirow{6}{*}{$0.006^{*}$} \\
\hline & & $\%$ & $100.0 \%$ & $23.5 \%$ & $76.5 \%$ & $69.2 \%$ & $30.8 \%$ & & \\
\hline & \multirow{2}{*}{ II } & $\mathrm{N}$ & 15 & 1 & 14 & 8 & 6 & & \\
\hline & & $\%$ & $100.0 \%$ & $6.7 \%$ & $93.3 \%$ & $57.1 \%$ & $42.9 \%$ & & \\
\hline & \multirow{2}{*}{ III } & $\mathrm{N}$ & 28 & 1 & 27 & 6 & 21 & & \\
\hline & & $\%$ & $100.0 \%$ & $3.6 \%$ & $96.4 \%$ & $22.2 \%$ & $77.8 \%$ & & \\
\hline \multirow{8}{*}{ 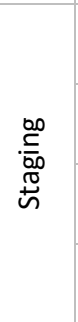 } & \multirow{2}{*}{ I } & $\mathrm{N}$ & 35 & 5 & 30 & 17 & 13 & \multirow{8}{*}{12.574} & \multirow{8}{*}{$0.049 *$} \\
\hline & & $\%$ & $100.0 \%$ & $14.3 \%$ & $85.7 \%$ & $56.7 \%$ & $43.3 \%$ & & \\
\hline & \multirow{2}{*}{ II } & $\mathrm{N}$ & 15 & 1 & 14 & 6 & 8 & & \\
\hline & & $\%$ & $100.0 \%$ & $6.7 \%$ & $93.3 \%$ & $42.9 \%$ & $57.1 \%$ & & \\
\hline & \multirow{2}{*}{ III } & $\mathrm{N}$ & 9 & 0 & 9 & 0 & 9 & & \\
\hline & & $\%$ & $100.0 \%$ & $.0 \%$ & $100.0 \%$ & $.0 \%$ & $100.0 \%$ & & \\
\hline & \multirow{2}{*}{ IV } & $\mathrm{N}$ & 1 & 0 & 1 & 0 & 1 & & \\
\hline & & $\%$ & $100.0 \%$ & $.0 \%$ & $100.0 \%$ & $.0 \%$ & $100.0 \%$ & & \\
\hline \multirow{6}{*}{ 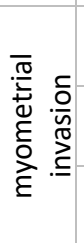 } & \multirow{2}{*}{ No } & $\mathrm{N}$ & 5 & 1 & 4 & 2 & 2 & \multirow{6}{*}{2.302} & \multirow{6}{*}{0.680} \\
\hline & & $\%$ & $100.0 \%$ & $20.0 \%$ & $80.0 \%$ & $50.0 \%$ & $50.0 \%$ & & \\
\hline & \multirow{2}{*}{$<50$} & $\mathrm{~N}$ & 15 & 1 & 14 & 4 & 10 & & \\
\hline & & $\%$ & $100.0 \%$ & $6.7 \%$ & $93.3 \%$ & $28.6 \%$ & $71.4 \%$ & & \\
\hline & $>50$ & $\mathrm{~N}$ & 40 & 4 & 36 & 17 & 19 & & \\
\hline & $>50$ & $\%$ & $100.0 \%$ & $10.0 \%$ & $90.0 \%$ & $47.2 \%$ & $52.8 \%$ & & \\
\hline
\end{tabular}

* Significant ( $\mathrm{P}$ value $<0.05$ )

positive expression. The relation between VEGF and histopathologic types, grade, myometrial invasion and stages of endometrial carcinoma cases was statistically significant as in Table 3 . As high expression of VEGF was associated with higher grade stages of endometrial carcinoma and myometrial invasion (Figure 3 and Tables $3,4,5)$.

\section{Correlation between different immunomarkers expression in atypical endometrial hyperplasia versus grade 1 endometrial carcinoma cases: Among the studied markers, only Ki-67 showed a statistically significant relation between atypical endometrial hyperplasia and grade I endometrial carcinoma cases ( $P$ value $=0.005)$. It was positive in (76.5\%) of grade 1 endometrial carcinoma cases and (30\%) of atypical endometrial hyperplasia cases (Table 5).}

\section{DISCUSSION}

The present study included 120 selected cases of endometrial lesions classified histologically into two major groups, group I constituted of 60 cases of endometrial hyperplasia, and group II constituted of 60 cases of endometrial carcinoma. The present work aimed to study the relationship between OCT-4, Ki-67and VEGF immunohistochemical expression and clinicopathologic data of endometrial hyperplasia and carcinoma.

OCT-4 is a transcription factor that forms a core regulatory network that determines endometrial cancer stem cells (ESC) selfrenewal and differentiation. These ESCassociated proteins may also contribute to tumorigenesis. OCT-4 expression was positive in $(86.7 \%)$ of endometrial carcinoma cases, with 
Table 3. The relation between VEGF and clinicopathologic parameters of endometrial carcinoma.

\begin{tabular}{|c|c|c|c|c|c|c|c|c|c|}
\hline & & & \multicolumn{5}{|c|}{ VEGF } & \multirow{2}{*}{\multicolumn{2}{|c|}{ Chi-square }} \\
\hline & & & \multirow[b]{2}{*}{ Total $\mathbf{N}=60$} & \multirow{2}{*}{$\begin{array}{c}\text { Negative } \\
\qquad \begin{array}{c}N=10 \\
(16.7 \%)\end{array}\end{array}$} & \multicolumn{3}{|c|}{$\begin{array}{c}\text { Positive } \\
\mathrm{N}=50(83.3 \%)\end{array}$} & & \\
\hline & & & & & Total +ve & $\begin{array}{c}\text { Moderate } \\
\qquad \begin{array}{l}N=16 \\
(32 \%)\end{array}\end{array}$ & $\begin{array}{c}\text { Strong } \\
N=34 \\
(68 \%)\end{array}$ & $x^{2}$ & P-value \\
\hline \multirow{8}{*}{ 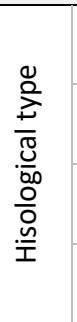 } & \multirow{2}{*}{ Endometrioid } & $\mathrm{N}$ & 38 & 10 & 28 & 15 & 13 & \multirow{8}{*}{23.983} & \multirow{8}{*}{$0.001^{*}$} \\
\hline & & $\%$ & $100.0 \%$ & $26.3 \%$ & $73.7 \%$ & $53.6 \%$ & $46.4 \%$ & & \\
\hline & \multirow{2}{*}{ Mucinous } & $\mathrm{N}$ & 2 & 0 & 2 & 1 & 1 & & \\
\hline & & $\%$ & $100.0 \%$ & $.0 \%$ & $100.0 \%$ & $50.0 \%$ & $50.0 \%$ & & \\
\hline & \multirow{2}{*}{ Papillary } & $\mathrm{N}$ & 10 & 0 & 10 & 0 & 10 & & \\
\hline & & $\%$ & $100.0 \%$ & $.0 \%$ & $100.0 \%$ & $.0 \%$ & $100.0 \%$ & & \\
\hline & \multirow{2}{*}{ Clear } & $\mathrm{N}$ & 10 & 0 & 10 & 0 & 10 & & \\
\hline & & $\%$ & $100.0 \%$ & $.0 \%$ & $100.0 \%$ & $.0 \%$ & $100.0 \%$ & & \\
\hline \multirow{6}{*}{$\frac{0}{\frac{0}{0}}$} & \multirow{2}{*}{1} & $N$ & 17 & 10 & 7 & 5 & 2 & \multirow{6}{*}{36.442} & \multirow{6}{*}{$0.001^{*}$} \\
\hline & & $\%$ & $100.0 \%$ & $58.8 \%$ & $41.2 \%$ & $71.4 \%$ & $28.6 \%$ & & \\
\hline & \multirow{2}{*}{ II } & $\mathrm{N}$ & 15 & 0 & 15 & 6 & 9 & & \\
\hline & & $\%$ & $100.0 \%$ & $.0 \%$ & $100.0 \%$ & $40.0 \%$ & $60.0 \%$ & & \\
\hline & \multirow{2}{*}{ III } & $\mathrm{N}$ & 28 & 0 & 28 & 5 & 23 & & \\
\hline & & $\%$ & $100.0 \%$ & $.0 \%$ & $100.0 \%$ & $17.9 \%$ & $82.1 \%$ & & \\
\hline \multirow{8}{*}{$\begin{array}{l}\stackrel{\infty}{\subseteq} \\
\cdot \frac{C}{00} \\
\stackrel{\pi}{n}\end{array}$} & \multirow{2}{*}{ I } & $N$ & 35 & 10 & 25 & 15 & 10 & \multirow{8}{*}{27.253} & \multirow{8}{*}{$0.001^{*}$} \\
\hline & & $\%$ & $100.0 \%$ & $28.6 \%$ & $71.4 \%$ & $60 \%$ & $40 \%$ & & \\
\hline & \multirow{2}{*}{ II } & $\mathrm{N}$ & 15 & 0 & 15 & 1 & 14 & & \\
\hline & & $\%$ & $100.0 \%$ & $.0 \%$ & $100.0 \%$ & $6.7 \%$ & $93.3 \%$ & & \\
\hline & \multirow{2}{*}{ III } & $\mathrm{N}$ & 9 & 0 & 9 & 0 & 9 & & \\
\hline & & $\%$ & $100.0 \%$ & $.0 \%$ & $100.0 \%$ & $.0 \%$ & $100.0 \%$ & & \\
\hline & \multirow{2}{*}{ IV } & $\mathrm{N}$ & 1 & 0 & 1 & 0 & 1 & & \\
\hline & & $\%$ & $100.0 \%$ & $.0 \%$ & $100.0 \%$ & $.0 \%$ & $100.0 \%$ & & \\
\hline \multirow{6}{*}{ 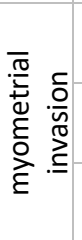 } & \multirow{2}{*}{ No } & $\mathrm{N}$ & 5 & 2 & 3 & 1 & 2 & \multirow{6}{*}{16.102} & \multirow{6}{*}{$0.003^{*}$} \\
\hline & & $\%$ & $100.0 \%$ & $40.0 \%$ & $60.0 \%$ & $33.3 \%$ & $66.7 \%$ & & \\
\hline & & $\mathrm{N}$ & 15 & 3 & 12 & 9 & 3 & & \\
\hline & $<50$ & $\%$ & $100.0 \%$ & $20.0 \%$ & $80.0 \%$ & $75.0 \%$ & $25.0 \%$ & & \\
\hline & & $\mathrm{N}$ & 40 & 5 & 35 & 6 & 29 & & \\
\hline & & $\%$ & $100.0 \%$ & $12.5 \%$ & $87.5 \%$ & $17.1 \%$ & $82.9 \%$ & & \\
\hline
\end{tabular}

* Significant ( $\mathrm{P}$ value $<0.05)$.

significant direct relation with the histopathological types, as it was positive in (78.9\%) of endometrioid carcinoma cases while positive in all cases of mucinous, papillary serous and clear types with the highest expression (score +2 ) in all cases of papillary serous, clear types and $73.3 \%$ and $50 \%$ of positive cases of endometroid and mucinous carcinoma types. However, Shorky et al., (2017) reported that OCT-4 expression in their study was positive in all cases of endometrial carcinoma with the highest expression in (37\%) of cases of type 1 carcinoma, whereas type 2 showed low expression. These discrepancies can probably be explained by the variations in methodology, principally differences in the specificity of antibody and dilution used.

In a present study, the highest expression of OCT-4 was positive in (100\%) of grade 3 endometrial carcinoma [Which included poorly differentiated endometrioid carcinoma, papillary serous type and clear cell type] with the highest expression (score +2 ) in (96.4\%) of cases of grade 3 . Also, in grade 2 endometrial carcinoma cases, it was positive (100\%), while it was only $52.9 \%$ in grade 1 endometrial carcinoma. It was found that there was a significant direct relation between OCT-4 immunohistochemical expression and grading of endometrial carcinoma cases; as higher expression of OCT-4 was related to higher tumor grade.

These findings were parallel to those of Xie et al. (2019) who found a significant direct relation between OCT-4 expression and FIGO grading of endometrial carcinoma in their series as OCT-4 expression was positive in all cases of grade 3 and grade 2 endometrial carcinoma, while it 
Table 4. Correlation of immunohistochemical results between the two studied groups (Endometrial hyperplasia and Endometrial carcinoma).

\begin{tabular}{|c|c|c|c|c|c|c|}
\hline & & Total & $-v e$ & +ve & $\mathrm{X}^{2}$ & P-value \\
\hline \multirow{2}{*}{ OCT-4 } & Endometrial hyperplasia & 60 & $47(78.3 \%)$ & $13(21.7 \%)$ & \multirow{2}{*}{51.052} & \multirow{2}{*}{$0.001^{*}$} \\
\hline & Endometrial carcinoma & 60 & $8(13.3 \%)$ & $52(86.7 \%)$ & & \\
\hline \multirow{2}{*}{ Ki- 67} & Endometrial hyperplasia & 60 & $54(90 \%)$ & $6(10 \%)$ & \multirow{2}{*}{76.801} & \multirow{2}{*}{$0.001^{*}$} \\
\hline & Endometrial carcinoma & 60 & $6(10 \%)$ & $54(90 \%)$ & & \\
\hline \multirow{2}{*}{ VEGF } & Endometrial hyperplasia & 60 & $52(86.7 \%)$ & $8(13.3 \%)$ & \multirow{2}{*}{58.871} & \multirow{2}{*}{$0.001^{*}$} \\
\hline & Endometrial carcinoma & 60 & $10(16.7 \%)$ & $50(83.3 \%)$ & & \\
\hline
\end{tabular}

* Significant ( $\mathrm{P}$ value $<0.05)$.

Table 5. Correlation of immunohistochemical results between atypical endometrial hyperplasia versus grade 1 endometrial carcinoma cases.

\begin{tabular}{|c|c|c|c|c|c|c|}
\hline & & Total & -ve & +ve & $\mathbf{X}^{2}$ & P-value \\
\hline \multirow{2}{*}{ OCT-4 } & Atypical endometrial hyperplasia & 20 & $7(35 \%)$ & $13(65 \%)$ & 0.552 & 0.457 \\
\cline { 2 - 6 } & Grade 1 endometrial carcinoma & 17 & $8(47.1 \%)$ & $9(52.9 \%)$ & & \\
\multirow{2}{*}{ Ki-67 } & Atypical endometrial hyperplasia & 20 & $14(70 \%)$ & $6(30 \%)$ & 7.942 & $0.005^{*}$ \\
\cline { 2 - 6 } & Grade 1 endometrial carcinoma & 17 & $4(23.5 \%)$ & $13(76.5 \%)$ & & \\
\hline \multirow{2}{*}{ VEGF } & Atypical endometrial hyperplasia & 20 & $12(60 \%)$ & $8(40 \%)$ & 0.012 & 0.942 \\
\cline { 2 - 6 } & Grade 1 endometrial carcinoma & 17 & $10(58.8 \%)$ & $7(41.2 \%)$ & & \\
\hline
\end{tabular}

* Significant ( $\mathrm{P}$ value $<0.05)$.
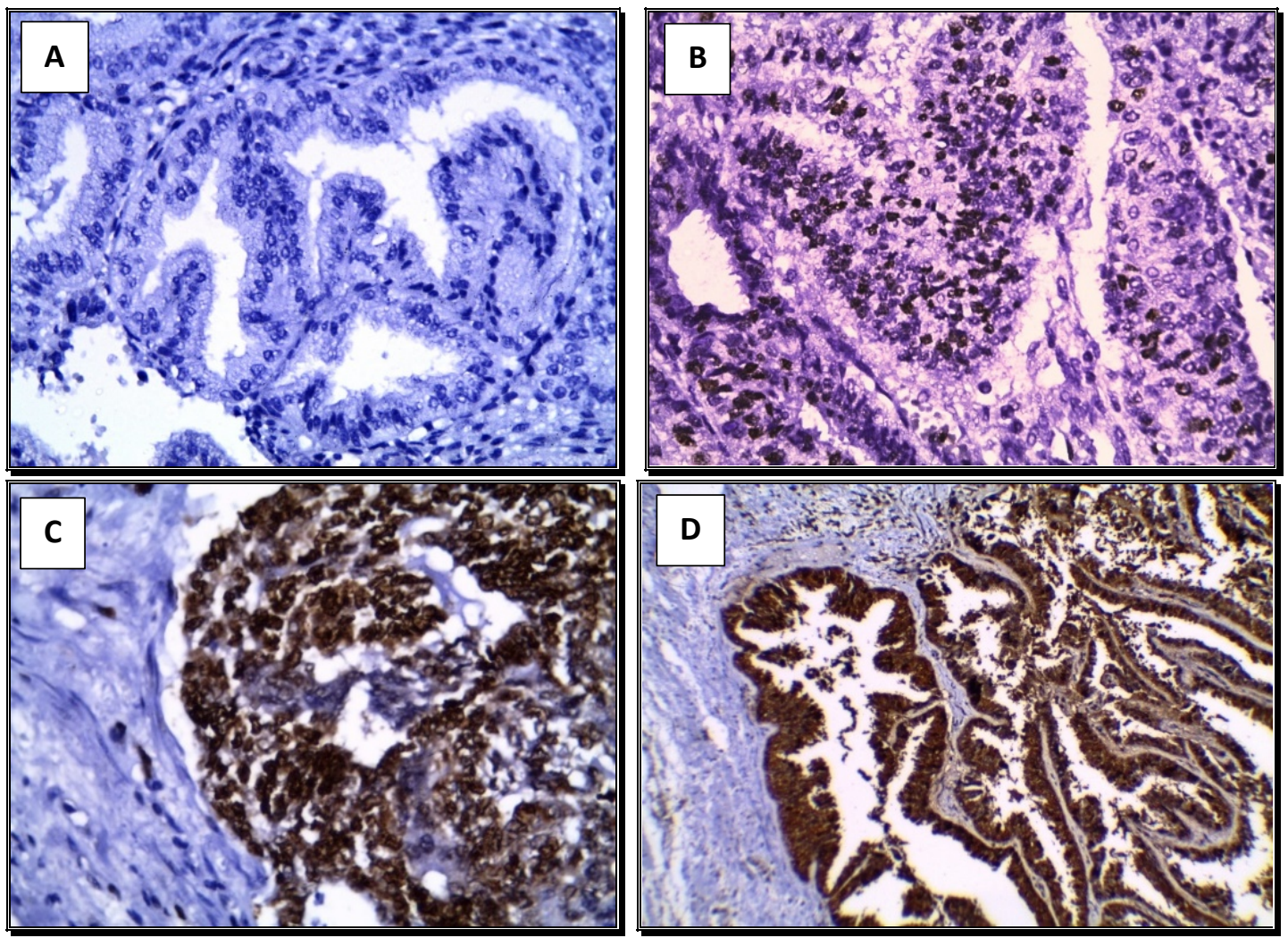

Figure 1. OCT4 Immunohistochemical expression A: case of complex endometrial hyperplasia showing score (0) nuclear expression of OCT-4 (X 400). B: Conventional endometrioid carcinoma (grade 2) showing score (+1) nuclear expression of OCT-4 (X 400). C: Conventional endometrioid carcinoma (grade 3), showing score (+2) nuclear expression of OCT-4 (X 400). D: A case of uterine papillary serous type, showing score $(+2)$ nuclear expression of OCT-4 (X 200). 


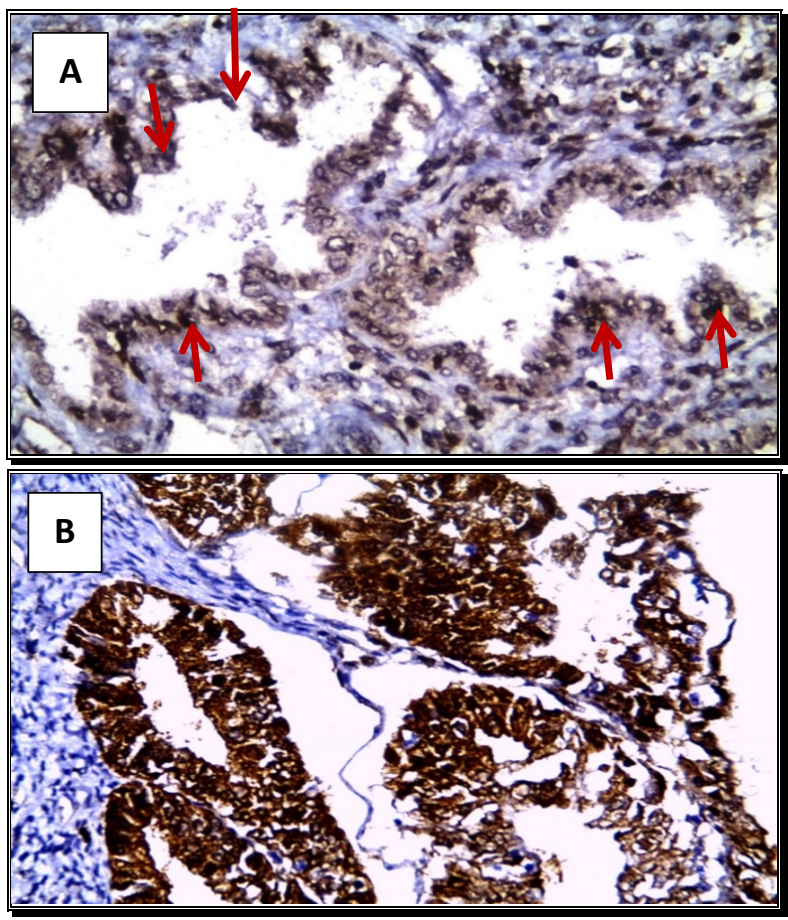

Figure 2. KI-67 Immunohistochemical expression A: a case of atypical endometrial hyperplasia showing low index nuclear expression of Ki-67 (X 400). B: Conventional endometrioid carcinoma (grade 1$)$, showing a high index nuclear expression of Ki-67 (X 400).

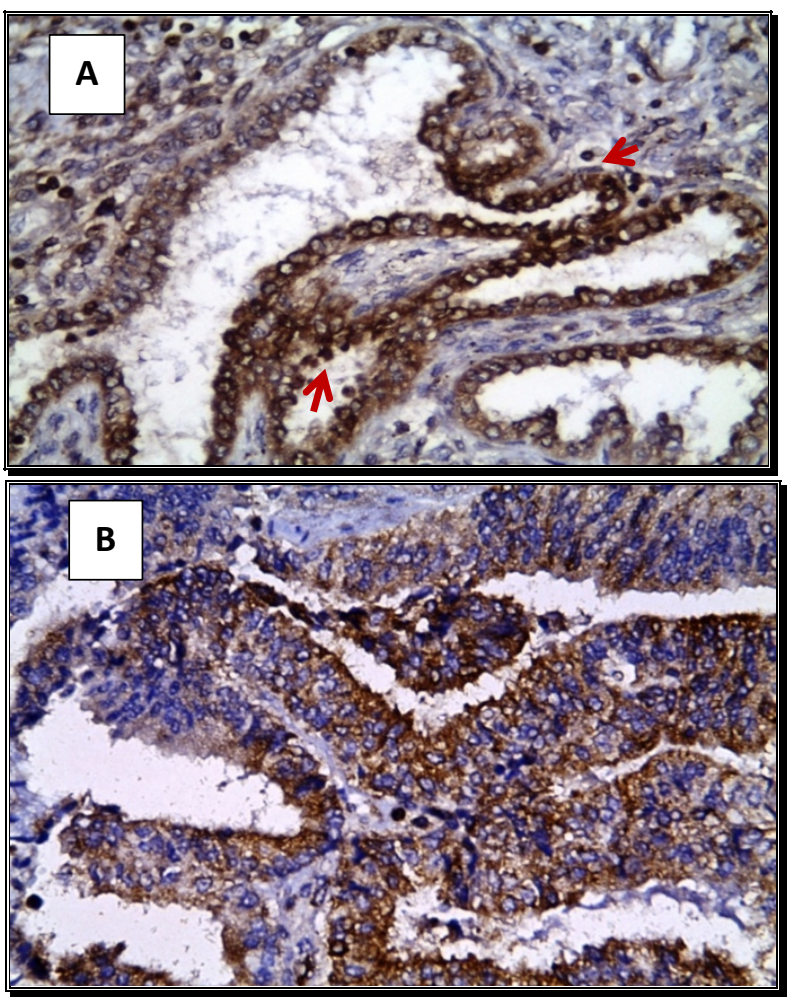

Figure 3. VEGF Immunohistochemical expression A: A case of atypical endometrial hyperplasia showing strong cytoplasmic expression for VEGF (X 400). B: A case of conventional endometrioid carcinoma (grade 3 ), showing strong VEGF expression (X 400). was only $50 \%$ in grade 1 endometrial carcinoma. On the other hand, Pityński et al. (2015) reported non-significant relation between OCT4 expressions and grade 1 and 2 endometrial carcinomas compared to grade 3 carcinomas.

OCT- 4 was positive in $60 \%$ of cases that did not show myometrial invasion, $86.7 \%$ of cases with invasion less than half the myometrium, and $90 \%$ of cases with invasion more than half the myometrial invasion. Although the relation between OCT4 and depth invasion did not reach a statistically significant relation, OCT4 was found to increase with the level of myometrial invasion, as it was positive in (90\%) of cases with myometrial invasion $>50 \%$.

OCT-4 was expressed in $77.1 \%$ of endometrial carcinoma stage I cases, and $100 \%$ positive in stages II, III and stage IV cases. The relation between OCT-4 immunohistochemical expression and stage of endometrial carcinoma reached significant value with a direct relationship. These results indicate that elevated expression of OCT-4 is positively associated with late-stage progression and worse prognosis of endometrial cancer patients. Xie et al. (2019) reported that OCT-4 is an important transcription factor that contributes to both tumor metastasis and chemoresistance. Kutilin et al. (2019) also, has been reported that poorly differentiated tumors exhibit highly activated embryonic stem cell signals with accumulating evidence that the activation of key transcription factors like OCT4 is important for tumor oncogenesis, progression and metastasis.

OCT4 was positive in only 13 cases (21.7\%) of endometrial hyperplasia, all of them were of atypical endometrial hyperplasia and in (86.7\%) of endometrial carcinoma cases. There was a significant difference between expression of OCT4 in endometrial hyperplasia and endometrial carcinoma cases but no significant difference could be found between atypical hyperplasia and carcinoma. Although the expression of OCT 4 might be an indicator for the progression of endometrial hyperplasia to carcinoma it could not be used as a diagnostic tool to differentiate between atypical endometrial hyperplasia and carcinoma. 
Shorky et al. (2017) reported the expression of OCT4 in nine cases (30\%) of endometrial hyperplasia cases out of total of 30 cases: two $(22.2 \%)$, four $(44.4 \%)$, and three $(33.3 \%)$ cases of simple endometrial hyperplasia, atypical endometrial hyperplasia and complex endometrial hyperplasia, respectively. This discrepancy in results to our study could be attributed to a small number of cases in their study.

$\mathrm{Ki}-67$ is a cellular marker for proliferation and it is an excellent marker to determine the growth fraction of a given cell population (Rossi et al., 2020). Regarding endometrial carcinoma cases, Ki-67 expression was positive in $90 \%$. It was found that there was a significant relation between Ki-67 expression and the histopathologic types of studied cases of endometrial carcinoma. It was positive in $84.2 \%$ of endometrioid carcinoma cases and positive in all cases $(100 \%)$ of mucinous type, papillary serous type and clear cell type of endometrial carcinoma with a high labelling index. There was a difference between the present study \& the results of $\mathrm{Yu}$ et al. (2015) regarding Ki-67 percentage as it was positive in (64.2\%) of endometrial carcinoma cases, may be due to the absence of aggressive types (uterine papillary serous carcinoma and clear cell carcinoma) in their study, which were completely positive for Ki-67 in our study.

In the present study, there was a significant direct relation between $\mathrm{Ki}-67$ expression and the grade of endometrial carcinoma cases, as Ki67 positive expression was lowest in grade 1 (76.5\%), while it represented $93.3 \%$ and $96.4 \%$ in grade 2 \& grade 3 cases respectively with high labelling index in $77.8 \%$ and $42.9 \%$ of grades 3 and 2 , respectively.

A progressive increase of $\mathrm{Ki}-67$ in grade 3 may be linked to tumor aggressiveness and loss of differentiation of endometrial cancer. This was in coincidence with the results of Gülseren et al., (2020). On the other hand, Yang et al., (2016), found an insignificant direct relation between the grade of endometrial carcinoma cases and $\mathrm{Ki}-67$ expression in their studied cases.

In relation to the depth of myometrial invasion, Ki-67 was positive in $80 \%$ of cases without myometrial invasion, $93.3 \%$ of cases with invasion less than half of the myometrium and $90 \%$ of cases with invasion more than half of the myometrium. Although the relation between $\mathrm{Ki}$ 67 and depth of myometrial invasion did not reach a statistical significance Ki-67 was found to be significantly related to stage.

As dealing with the staging of endometrial carcinoma cases, the present study proved that there was a significant direct relation between $\mathrm{Ki}-67$ expression and stage as $\mathrm{Ki}-67$ expression was positive in $100 \%$ of stage IV cases and stage III cases, $93.3 \%$ of stage II cases and $85.7 \%$ of stage I cases. So, those cancers with the greatest cell proliferation had the poorest clinical outcome and are more likely to be associated with disease metastasis and recurrence. This was in agreement with the findings of Furau et al., (2019), who found also a positive relation between $\mathrm{Ki}-67$ expression on one hand with stage and depth of myometrial invasion.

In the present study, 6 out of 60 cases of endometrial hyperplasia were positive for Ki-67 immunoreactivity, representing $10 \%$ (all of these six cases were atypical hyperplasia with low labelling index). This can be explained by the increase in the malignant potential of atypical endometrial hyperplasia cases. This is in agreement with the findings of Zimik et al. (2020) who did not find expression of Ki-67 in nearly all their studied cases of endometrial hyperplasia without atypia.

Ki-67 expression in endometrial carcinoma cases $(90 \%)$ was significantly higher than that of endometrial hyperplasia cases (10\%). Also, there was a significantly higher Ki-67 expression in grade1 endometrial carcinoma cases (76.5\%) than that of atypical endometrial hyperplasia cases $(30 \%)$. This finding was in coincidence with that of Shalini et al., (2019) who found that there was a significant positive relationship between $\mathrm{Ki}-67$ expression in endometrial hyperplasia and endometrial carcinoma. So, the Ki-67 labelling index could be used in differentiation between endometrial hyperplasia with atypia and grade 1 endometrial carcinoma. Further studies on a larger number of cases are needed to reach a cut-off value for $\mathrm{Ki} 67$ in the diagnosis of 
endometrial carcinoma and differentiation between atypical endometrial hyperplasia and grade 1 endometrial carcinoma.

Both tumor cell proliferation (Ki-67) and angiogenesis seem to be important for the development of aggressive tumors and to carry an independent significance for the tumor growth potential. Hence, the present research attempted to examine the expression of VEGF in endometrial hyperplasia and endometrial carcinoma, to characterize its relationship with a set of clinicopathologic characteristics.

Most of the endometrial carcinoma cases (83.3\%) showed VEGF positive expression, with significant relation with histopathological types of endometrial carcinoma cases. VEGF expression was highest in grade 2 and grade 3 endometrial carcinoma (100\%) and decreased expression in grade 1 (41.2\%) cases. It was found that there was a significant direct relation between VEGF expression and grade of endometrial carcinoma. This was in agreement with the results of Wang et al. (2014).

Strong positivity for VEGF in grade 2 and grade 3 carcinoma could be explained that VEGF plays a role in tumor progression. This was in coincidence with Zinovkin et al. (2019), who found low VEGF expression in welldifferentiated endometrial carcinoma cases in comparison to poorly differentiated cases.

VEGF had a significant relationship with a depth of myometrial invasion, as it was positive in $87.5 \%$ of cases with an invasion with more than half the myometrium, $80 \%$ of cases that show invasion less than half of the myometrial, and $60 \%$ of cases without myometrial invasion. As regards the stage of endometrial carcinoma, VEGF was expressed in all cases of stage IV, stage III and stage II (100\%), while it was found in $(71.4 \%)$ of stage I tumours with significant relation with the stage. This finding was in coincidence with Sunita et al. (2018) who reported that VEGF expression occurred more often in endometrial cancers with deep myometrial invasion.

These results emphasize the role of VEGF in carcinogenesis as it is a potent pro-angiogenic factor and also a key mediator of neovascularization, a process that is mandatory in the pathogenesis of malignant tumors. its overexpression in tumor cells stimulates tumor growth and metastasis in cancer (Guşet et al., 2010; Sunita et al., 2018).

In the present study 52 out of 60 cases of endometrial hyperplasia didn't show positivity for VEGF, while only 8 cases of atypical endometrial hyperplasia were positive for VEGF with a strong expression representing (13.3\%) of cases. There was a significant higher VEGF expression in endometrial carcinoma cases (83.3\%) than that of endometrial hyperplasia cases $(13.3 \%)$. This finding was in coincidence with that of Hassan and Ibrahim, (2020) who found that there is a higher expression of VEGF in endometrial carcinoma to hyperplasia with a significant relationship. But, there was weak cytoplasmic positive staining in atypical endometrial hyperplasia while in benign endometrial hyperplasia, the expression was negative.

These results emphasize that high expression of VEGF seems to have a role in the progression of endometrial hyperplasia into endometrial carcinoma. However, as regards the relation of VEGF expression in atypical endometrial hyperplasia versus grade 1 endometrial carcinoma; it was insignificant which explain that VEGF could not be used as a diagnostic tool in differentiation between them.

\section{CONCLUSION}

OCT-4, Ki-67 and VEGF expression showed a positive correlation with tumor aggressive pathological parameters. The Ki-67 labelling index can be used in differentiation between endometrial hyperplasia with atypia and grade 1 endometrial carcinoma. Although OCT-4 and VEGF expressed in endometrial cancer more than hyperplasia, they could not be used as diagnostic tools to differentiate between atypical endometrial hyperplasia and carcinoma. However, it indicates that they have a role in malignant transformation.

\section{CONFLICTS OF INTEREST}

All authors have approved this article and declare no conflicts of interest.

\section{FUND}

No fund was received for this work. 


\section{References}

Furau A, Craina ML, Furau C, Luca TC, Andor BC, Radu D , Furau G (2019). The Association of Body Mass Index and Ki67 Values in Patients with Endometrial Carcinoma. REVISTA DE CHIMIE, 70: 3277-3280.

Gülseren V, Kocaer M, Özdemir IA, Çakır I, Sanci M \& Güngördük K (2020). Do estrogen, progesterone, P53 and Ki67 receptor ratios determined from curettage materials in endometrioid-type endometrial carcinoma predict lymph node metastasis?. Current Problems in Cancer, 44: 100498.

Guşet G, Costi S, Lazăr E, Dema A, Cornianu M, Vernic $C \&$ păiuşan $L(2010)$. Expression of vascular endothelial growth factor (VEGF) and assessment of microvascular density with CD34 as prognostic markers for endometrial carcinoma. Romanian Journal of Morphology and Embryology, 51:677-682.

Hassan WA and Ibrahim R (2020) Expression of CD117, CD34, and VEGF proteins in progression from endometrial hyperplasia to endometrioid carcinoma. International Journal of Clinical \& Experimental Pathology, 13: 2115-2122.

Kurman RJ, Carcangiu ML, Herrington S, Young RH (2014).Tumours of the female reproductive organs. WHO classification of tumours. IARC Press, Lyon.

Li M, Zhao L, Qi W, Shen D, Li X, Wang J \& Wei L (2013). Clinical implications and prognostic value of five biomarkers in endometrial carcinoma. The Chinese-German Journal of Clinical Oncology, 12(12), 586-591.

Lu H, Xie Y, Tran L, Lan J, Yang Y, Murugan NL \& Semenza GL (2020). Chemotherapy-induced S100A10 recruits KDM6A to facilitate OCT4mediated breast cancer stemness. The Journal of Clinical Investigation 130 (9):4607-4623.

Malpica A, Euscher ED, Hecht JL, Ali-Fehmi R, Quick CM, Singh N \& Duggan M. (2019). Endometrial carcinoma, grossing and processing issues: recommendations of the International Society of Gynecologic Pathologists. International Journal of Gynecological Pathology, 38 (1 Suppl 1), $\mathrm{S9.}$

Masjeed, NMA, Khandeparkar SGS, Joshi AR, Kulkarni MM \& Pandya N (2017). Immunohistochemical study of ER, PR, Ki67 and p53 in endometrial hyperplasias and endometrial carcinomas. Journal of clinical and diagnostic research: JCDR, 11: EC31.

Melincovici CS, Bos, ca AB, S, us, man S, et al. (2018). Vascular endothelial growth factor (VEGF): key factor in normal and pathological angiogenesis. Romanian Journal of Morphology and
Embryology. 59: 455-67

Murali R, Soslow RA, \& Weigelt B (2014). Classification of endometrial carcinoma: more than two types. The Lancet Oncology, 15: e268e278.

Pityński K, Banas T, Pietrus M, Milian-Ciesielska K, Ludwin A \& Okon K (2015). SOX-2, but not Oct4, is highly expressed in early-stage endometrial adenocarcinoma and is related to tumour grading. International journal of clinical and experimental pathology, 8: 8189-8198.

Rossi L, Verrico M, Tomao S, Ricci F, Fontana A, Spinelli GP\& Tomao F (2020). Expression of ER, PR, HER-2, and Ki-67 in core biopsies and in definitive histological specimens in patients with locally advanced breast cancer treated with neoadjuvant chemotherapy. Cancer Chemotherapy and Pharmacology. 85: 105111.

Shalini P, Suresh N, \& Ganapathy H (2019). Ki-67 Expression in Endometrial Hyperplasia. Indian Journal of Public Health Research \& Development, 10: 4050-4053.

Shorky NH, Mohmoud NB, Abdel HM, Cousha HS \& Ibrahim EA (2017). Immunohistochemical expression of stem cell markers CD133 and Oct4 in cases of endometrial hyperplasia and endometrial carcinoma. Egyptian Journal of Pathology, 37: 154-159.

Sunita B, Sen A \& Suhag V (2018) To evaluate immunoreactivity of cyclooxygenase- 2 in cases of endometrial carcinoma and correlate it with expression of p53 and vascular endothelial growth factor. Journal of cancer research and therapeutics, 14:1366-72.

Wang J, Taylor A, Showeil R, Trivedi P, Horimoto Y, Bagwan I \& El-Bahrawy MA. (2014). Expression profiling and significance of VEGF-A, VEGFR2, VEGFR3 and related proteins in endometrial carcinoma. Cytokine, 68:94-100.

Xie P, Wang X, Kong M, Bai X \& Jiang T (2019). TRAF4 promotes endometrial cancer cell growth and migration by activation of PI3K/AKT/Oct4 signaling. Experimental and Molecular Pathology, 108: 9-16.

Yang B, Shan B, Xue X, Wang H, Shan W, Ning C \& Luo $X$ (2016). Predicting lymph node metastasis in endometrial cancer using serum CA125 combined with immunohistochemical markers PR and Ki67, and a comparison with other prediction models. PloS one, 11: e0155145.

Yang BY, Gulinazi Y, Du Y, Ning CC, Cheng YL, Shan WW \& Liu J (2020). Metformin plus megestrol acetate compared with megestrol acetate alone as fertility-sparing treatment in patients with atypical endometrial hyperplasia and welldifferentiated endometrial cancer: a 
randomised controlled trial. BJOG: An International Journal of Obstetrics \& Gynaecology, 127: 848-857.

Yu CG, Jiang XY, Li B, Gan L, Huang JF (2015). Expression of ER, PR, CerbB-2 and Ki-67 in endometrial carcinoma and their relationships with the clinicopathological features. Asian Pacific Journal of Cancer Prevention, 16: 67896794.

Zhou X, Zhou YP, Huang GR, Gong BL, Yang B, Zhang DX \& Xu SR (2011). Expression of the stem cell marker Nanog in human endometrial adenocarcinoma. International journal of gynecological pathology: official journal of the International Society of Gynecological
Pathologists, 30:262-274.

Zimik T, Longjam D \& Devi S (2020): a study of histopathological spectrum of endometrial lesions in abnormal uterine bleeding with analysis of expression pattern of er, pr and ki67. Paripex-Indian Journal Of Research, 9(6):14.

Zinovkin DA, Achinovich SL, Zubritskiy MG, Whatmore JL \& Pranjol MZI (2019). High Expression of Galectin-1, VEGF and Increased Microvessel Density Are Associated with MELF Pattern in Stage I-III Endometrioid Endometrial Adenocarcinoma. Journal of Pathology and Translational Medicine, 53: 280-288. 


\section{Egyptian Association for Cancer Research (EACR)}

http://eacr.tanta.edu.eg/

EACR is an NGO society that was declared by the Ministry of Social Solidarity (Egypt) No. 1938 in 19/11/2014 based on the initiative of Prof. Mohamed Labib Salem, the current Chairman of EACR. EACR aims primarily to assist researchers, in particular young researchers in the field of cancer research through workshops, seminars and conferences. Its first international annual conference entitled "Anti-Cancer Drug Discovery" was successfully organized in April 2019 (http://acdd.tanta.edu.eg). Additionally, EACR aims to raise the awareness of the society about the importance of scientific research in the field of cancer research in prediction, early diagnosis and treatment of cancer. EACR is also keen to outreach the scientific community with periodicals and news on cancer research including peer-reviewed scientific journals for the publication of cutting-edge research. The official scientific journal of EACR is "International Journal of Cancer and biomedical Research (IJCBR: https://jcbr.journals.ekb.eg) was successfully issued in 2017 and has been sponsored by the Egyptian Knowledge Bank (EKB: www.ekb.eg).

\section{EACR Chairman,}

Prof. Mohamed Labib Salem, PhD

Professor of Immunology

Faculty of Science, Tanta Universiy, Egypt 
International Journal of Cancer and Biomedical Research (IJCBR), a publication of the Egyptian Association for Cancer Research (EACR), is a peer-reviewed online journal published quarterly. The journal allows free access (Open Access) to its contents and permits authors to self-archive a final accepted version of the articles on any OAl-compliant institutional / subject-based repository.

\section{Aim And Scope}

Aim: The main aim of IJCBR is to attract the best research in animal and human biology in health and diseases from across the spectrum of the biomedical sciences at the molecular, cellular, organ, and whole animal levels especially those that are related to cancer research, including causes, prediction, diagnosis, prognosis and therapy.

Scope: It is essential reading for all researchers interested in biochemistry, cancer, microbiology, nutrition, physiology, genetics, immunology, epidemiology, medical economics, human biology, bioinformatics, biotechnology, nanotechnology, and disease modeling.

\section{Publication Ethics}

Researchers should conduct their research from research proposal to publication in line with the best practices and codes of conduct of relevant professional bodies and/or national and international regulatory bodies. IJCBR accepts manuscripts prepared in accordance with the "Uniform Requirements for Submission of Manuscripts for Biomedical Journals adopted by the International Committee of Medical Journal Editors (ICMJE) and the Committee on Publication Ethics (COPE). Details of ICMJE and COPE are available at http://www.icmje.org/ and http://publicationethics.org/

\section{Peer Review Process}

After the IJCBR editor receives a manuscript, the first step is to confirm that the manuscript meets the journal's rules for content and format, including similarity check (plagiarism) which should be less than $25 \%$. If the manuscript meets the journal's rules, the editor then assign it to the double-blind peer review process. The IJCBR editor send the manuscript to at least two experts in the field for RIGOROUS scientific evaluation. The experts called peer reviewers - will then prepare a report that assesses the manuscript and return it to the editor through the IJCBR portal. Upon the first submission, this reviewing process takes about 4 to 6 weeks. After reading the peer reviewer's report, the editor will decide one of the following four options:

1. Reject the manuscript.

2. Accept the manuscript

3. Ask the authors to revise and resubmit the manuscript after responding to the peer reviewers' feedback.

4. Ask for peer-review from additional reviewers.

If the authors resubmit the manuscript, the IJCBR editor will ask the same peer-reviewers to look over the manuscript again to confirm that their concerns have been addressed. This is called re-review process. This second revision (if applicable) takes about another 4 to 6 weeks. At this point, the abstract of the article appears in press. The online publication (the PDF format) of the final version of the manuscript takes from 2 to 4 weeks. As such, the total publication cycle takes from 2 to 4 months. This cycle can be reduced to 4 to 6 weeks (fast track publication) for the manuscripts with outstanding findings.

The peer-review process used by IJCBR includes comments on errors in the study's methods or analysis that raise questions about the findings, or sections that need clearer explanations. The peer-review process also includes the importance and novelty of the manuscript and its interest to the journal's audience. The IJCBR uses double-blind review, which means that both the reviewers and authors identities are concealed from the reviewers, and vice versa, throughout the review process. To facilitate this, authors need to submit a Title Page containing the Authors details and Blinded Manuscript with no author details as 2 separate files. 


\section{Publisher}

The International Journal of Cancer and Biomedical Research (IJCBR) is an International and interdisciplinary journal of preclinical and clinical studies in the area of cancer and biomedical research. It is a peer-reviewed journal in English, published quarterly (in March, June, September, and December) by the Egyptian Association for Cancer Research (EACR) in both print and online formats (4 issues making a volume). Special issues or supplements may also be produced from time to time upon agreement with the Editorial Board.

\section{Scope}

The main aim of IJCBR is to attract the best research in animal and human biology in health and diseases from across the spectrum of the biomedical sciences at the molecular, cellular, organ, and whole animal levels especially those that are related to cancer research, including causes, prediction, diagnosis, prognosis and therapy.

\section{Publication Fees}

The journal does charge for submission, processing or publication of manuscripts (2000 LE for Egyptians or $\$ 300$ for non-Egyptians; EACR members receive 15\% discount on publication). Of them Peer-review fees (300 LE) should be paid on submission (non-refundable). For the fast track production of the accepted manuscript, another $500 \mathrm{LE}$ is paid.

General specifications for different types of article

- Submitted manuscripts should not have been published previously, except in a limited form (e.g. short communication to a symposium or as part of MSc or PhD theses) and should not be under consideration for publication by other journals.

- All co-authors should agree with the content of the manuscript. Authors must have obtained permission to use any copyrighted material in the manuscript before submission.

\section{IJCBR publishes different types of articles}

- Original Article (6000 words with $\mathbf{4}$ tables and $\mathbf{4}$ figures, maximum $\mathbf{8}$ display items): Articles with novel findings are the target of IJCBR. Articles presenting a detailed description of a new technique, comparison of existing methods, meta-analyses with comprehensive and in-depth discussion are considered. Papers in a numbered series are not accepted unless all are submitted at the same time.

- Short communications or case study (3000 words with 4 display items): Short communications present exceptionally exciting, novel or timely contents are considered. They will be peer-reviewed in the same way as research papers. The references are restricted to 15 .

- Reviews or systematic review (9000 words with $\mathbf{1 0}$ display items): They are invited by the Editorial Board or unsolicited. Review articles have to be contemporary and comprehensive and add information to the knowledge. Sharp critical analyses of novel data or concepts are encouraged. When relevant, a statistical analysis of data and a meta-analysis approach are recommended.

- Opinion papers, letter to the editor or comment to the editor (1500 words with $\mathbf{2}$ display items): They are submitted by invitation of the Editorial Board. They are short papers, which aim to inform scientists, industry, and the public and policymakers about cutting-edge issues in research or the impact of research. They reflect the opinion of their authors who bear full responsibility of the published paper. The references are restricted to 10 .

- Conference/Symposium papers: The journal will consider for publication the results of original work and critical reviews that are presented at conferences/symposia. Symposium organizers who wish to publish bundles of papers from a symposium/conference in IJCBR should first contact the Editor-inChief of the IJCBR (EACR@unv.tanta.edu.eg) for agreement. Supplementary material can be proposed and will be made available online. The responsibility for the preparation of a paper in a form suitable for publication lies with the author.

- Thesis: IJCBR can publish the summary and abstract of Master and PhD theses in a special issue. 
English: Good quality of written English is required. Spelling may be in British or American English but must be consistent throughout the paper. Care should be exercised in the use of biological terminology that is ill-defined or of local familiarity only. We recommend that authors have their manuscripts checked by an English language native speaker before submission.

Manuscript layout: Manuscripts should be prepared using a standard word processing program and presented in a clear readable format with easily identified sections and headings. The manuscript layout is based on the following directions.

- The main text contains Title, Abstract, Keywords, Introduction, Material and Methods, Results, Discussion, References, Tables, figures.

- The title needs to be concise and informative. Use bold, with an initial capital for the first word only and for words that ordinarily take capitals

- Short (running) title (max 80 characters including spacing).

- The article text should be typed with double-line spacing with wide margins $(2.5 \mathrm{~cm})$.

- The lines must be continuously numbered; the pages must also be numbered.

- Font Calibri 12 should be used for the text, and 12 for the tables, figure legends and references.

- The sections should typically be assembled in the following order:

- Title page contains title, authors' names, full affiliations, acknowledgements and the corresponding author's contacts and Short title.

Abstract (max 250 words, single paragraph): The abstract should be complete and understandable without citation, references, table or figure. Use structured abstract: Background, Aim, Materials \& Methods, Results and Conclusion. The context and the rationale of the study are presented succinctly to support the objectives. The experimental methods and main results are summarized but should not be overburdened by numerical values or probability values. The abstract ends with a short and clear conclusion.

Keywords: Up to five short and specific keywords should complement the title with respect to indicating the subject of the paper in alphabetic order.

Introduction: The introduction briefly outlines the context of the work, presents the current issues that the authors are addressing and the rationale to support the objectives, and clearly defines the objectives.

Material and methods: Material and methods should be described in sufficient details so that others can repeat the experiment. Reference to previously published work may be used to give methodological details, provided that said publications are readily accessible and in English. The code of ethics should be followed for all experiments use animals or human samples.

Statistical analysis of results: The statistical design and the models of statistical analysis must be described, as well as each of the statistical methods used. Sufficient statistical details must be given to allow replication of the statistical analysis. The experimental unit should be defined (e.g. individual or group of animals).

Results: Data are presented as tables and figures. Brief description of the results for each table and figure should be presented. Unpublished data can be mentioned when necessary.

Discussion: Should be separate from the Results section and should focus only on intra- and inter-data discussion (the data in the results section) as well as with the relative data in the literature. Don't repeat information already presented in the Introduction section. Start the first paragraph in the Discussion with a paragraph stating the rationale behind the study, the objectives and the main findings. End Discussion with a short conclusion.

Acknowledgements: In this section, the authors may acknowledge (briefly) their support staff.

Conflict of interest: All papers with a potential conflict of interest must include a description/explanation in a separate heading.

Funding details: The authors should state the source of findings of the study (with research funder and/or grant number). If no fund, the authors should state that the study is self-funded. 


\section{References}

Citation of references: In the text, references should be cited by the author(s) surname(s) and the year of publication (e.g. Salem, 2020). References with two authors should be cited with both surnames (e.g. Salem and Meshrif, 2021). References with three or more authors should be cited with the first author followed by et al. (in italics; e.g. Salem et al., 2021). Names of organizations used as authors (e.g. Food and Drug Administration) should be written out in full in the list of references and on the first mention in the text. Subsequent mentions may be abbreviated (e.g. FDA).

- List of references. Literature cited should be listed in alphabetical order by authors' names. It is the author's responsibility to ensure that all references are correct. All authors should be written and so the full journal name.

- References from journal articles are formatted in APA as this example: Al-Amoudi WM (2018). Toxic effects of Lambda-cyhalothrin on the rat thyroid. Involvement of oxidative stress and ameliorative effect of ginger extract. Toxicology Reports, 5: 728-736.

- References from books or official reports are formatted as this example. Kebreab E, Dijkstra ANM, Bannink A, Gerrits WJJ, \& France J (2006). Nutrient digestion and utilization in farm animals. CABI Publishing. Wallingford, UK.

- References from chapters or parts of books are formatted as this example. Nozière $P, \&$ Hoch $T$ (2006). Modelling fluxes of volatile fatty acids from rumen to portal blood. In: Nutrient digestion and utilization in farm animals (Kebreab E, Dijkstra ANM, Bannink A, Gerrits WJJ \& France J, eds.), pp. 40-47. CABI Publishing. Wallingford, UK.

Tables:

The data should be presented in tables or in graphs, not both.

- Each table should be placed on a separate page at the end of the main text.

- Tables are numbered consecutively using Arabic numbering. They are referred to as Table 1 , Table 2, etc., with capital ' $T$ ', no italics

- Each table has its explanatory caption. The caption is sufficient to permit the table to be understood without reference to the text.

- Abbreviations used in tables/figures have to be defined either as footnotes or in the caption.

Figures

- Package the figures in a single PowerPoint file. Each figure in a separate slide.

- Figure size should be readable in a width of approximately 8-175 $\mathrm{mm}$ (i.e. the maximum size of printing over two columns).

- Ensure that the font size is large enough to be readable at the final print size, use Calibri font to ensure that they are consistent throughout the figures.

- The figures should preferably be provided as TIFF or EPS files.

- The resolutions of figures must be at least $300 \mathrm{dpi}$.

- Preparation of images for a manuscript: For guidance, we refer to the Journal of Cell Biology's instructions to authors (http://jcb.rupress.org/site/misc/ifora.xhtml\#image_aquisition).

- If a cropped image is included in the main text of a paper (e.g. a few lanes of a gel), display the full original image, including the appropriate controls, the molecular size ladder and/or the scale as relevant, as a single figure in a Supplementary Material file to facilitate peer-review and for subsequent online publication.

- Supplementary material is submitted along with the main manuscript in a separate file and identified at uploading as "Supplementary File - for Online Publication Only" The title of the article is included at the top of the supplementary material.

Corresponding author's guidelines: Upon acceptance the corresponding author is required to send his/her recent formal photo to be attached to the front page of the article. 


\title{
International Journal of Cancer \& Biomedical Research
}

(IJCBR) Online ISSN 2682-2628

\author{
Editor-in-Chief \\ Mohamed Labib Salem, PhD \\ Tanta University, Egypt
}

\begin{tabular}{l} 
EACR Board \\
\hline Nehal Elmashad, MD \\
Tanta University, Egypt \\
Nabil Mohy Eldin, PhD \\
Kafrelsheikh University, Egypt \\
Doaa Al-Ghareeb, PhD \\
Alexandria University, Egypt \\
Abdel-Aziz Zidan, PhD \\
Damanhour University, Egypt
\end{tabular}

\begin{tabular}{l} 
Managing Editor \\
\hline Wesam Meshrif, PhD \\
Tanta University, Egypt \\
Sohaila Galal, PhD \\
Tanta University, Egypt \\
Production and Contact \\
\hline Hamdi Kandil \\
Tanta University, Egypt \\
Email: ljcbr100@gmail.com
\end{tabular}

\section{Advisory Board}

Alberto Montero, MD

Taussig Cancer Center, Cleveland,

USA

Yi Zhang, MD

Zhengzhou University, China

Mark Robunstein, Ph D

Medical University of South

Carolina, USA

Mohsen Farid, Ph D

Derby University, USA

Natarajan Muthusamy, Ph D

Ohio State University, USA

Hideki Kasuya, MD

Nagoya University, Japan

Sherif El-Khamisy, Ph D

Sheffield University, UK

Mohamed Ghanem, Ph D

Kafr Elshikh University, Egypt

Sayed Bakry, Ph D

Alazhar University, Egypt

Sameh Ali, Ph D

Nationa Liver Institute, Egypt

Gamal Badr, Ph D

Assuit University, Egypt

Nadia Hamdy, Pharm D

Ain Shams University, Egypt

\section{Editorial Board}

\section{Clinical studies}

Hesham Tawfik, MD

Tanta University, Egypt

Mohamed Attia, MD

Tanta University, Egypt

Mohamed Elshanshory, MD

Tanta University, Egypt

Essam Elshiekh, MD

Tanta Cancer Center, Egypt

Rasha Eraky, MD

Tanta University, Egypt

Shaima Abou-Kjatwa, MD

Tanta University, Egypt

Marcela Diaz, MD

Cleveland Clinic Foundation, USA

Mohamed Abou-El-Enein, MD

Charité Universitätsmedizin Berlin,

Germany
Alaa Eldin Almostafa, MD

McGill University, Canada

Olfat Gadallah, MD

Tanta University, Egypt

Nagla Sarhan, MD

Tanta University, Egypt

Naglaa Fathy, Pharm D

Zagazik University, Egypt

Mohamed Salama, MD

Mansoura University, Egypt

Mona Marie, MD

Alexandria University, Egypt

Preclinical studies

Mostafa El-Sheekh

Tanta University, Egypt

El-Refai Kenawy, Ph D

Tanta University, Egypt

Mohamed Noureldin, Ph D

Banaha University, Egypt

Yousry Albolkiny, Ph D

Tanta University, Egypt

Elsayed Salim, Ph D

Tanta University, Egypt

Shengdian Wang, Ph D

Chinese Academy of Sciences,

China

Sabry El Naggar, Ph D

Tnata Univesity, Egypr

Faris Alenzi, Ph D

Prince Sattam bin Abdulaziz

University, KSA

Ibrahim El-Sayed, Ph D

Menoufia University, Egypt

Tarek Aboul-Fadl, Ph D

Assiut University, Egypt

Rabab Khairat, Ph D

National Research Center,

Giza, Egypt

Wael Lotfy, Ph D

Alexandria University, Egypt

Ashraf Tabll, Ph D

National Research Center, Egypt

Nahla Shoukry, Ph D

Suez University, Egypt
Medhat Eldenary, Ph D

Tanta University, Egypt

Azza Hasan, Ph D

Menufia University, Egypt

Nanees Gamal Eldin, Ph D

Tanta University, Egypt

Mohamed Mansour, UK

Sabbah Hammoury, Ph D

Alexandria Ayadi Almostaqba

Oncology Hospital, Egypt

Nehal Aboulfotoh, Ph D

Zewail City for Science and

Technology, Cairo, Egypt

Amir Elkhami, Ph D

Galaxo, San Francisco, USA

Ahmed Alzohairy, Ph D

Zagazi University, Egypt

Wgady Khalil, Ph D

National Research Center, Egypt

Amr Amin, Ph D

United Arab Emirates

University, UAE

AbdelRahman Zekri, Ph D

National Cancer Institute, Egypt

Hussein Khamis, Ph D

Alexandria University, Egypt

Magdy Mahfouz, Ph D

Kafr Elsheikh University, Egypt

Ehab Elbedewey, Ph D

Tanta University, Egypt

Abeer Badr, Ph D

Cairo University, Egypt

Mamdooh Ghoneum, Ph D

Charles Drew University of

Medicine \& Science, USA

Haiam Abou Elela, Ph D

National Institute of Oceanography and Fisherie, Egypt

Maha EL-Demellawi, Ph D City for Scientific Research \&

Technology Applications, Egypt

Desouky Abd-El-Haleem, Ph D

City for Scientific Research \&

Technology Applications, Egypt 